\title{
A Family with Adult Type Ceroid Lipofuscinosis (Kufs' Disease) and Heart Muscle Disease: Report of Two Autopsy Cases
}

\author{
Ken-ichi Sakajiri, Nae Matsubara, Takashi NaKajima, Nobuyoshi Fukuhara, Takao Makifuchi*, \\ Masatoshi WaKABAYASHI**, Shinsaku OyAnAGI*** and Eiki KominAmI****
}

Two cases in a family with Kufs' disease had lethal arrhythmias and heart muscle disease. Autopsy findings showed an abundant accumulation of lipofuscin-like lipopigments in most neurons in the central nervous system (CNS). The heart showed a slight increase in the accumulation of the lipofuscin-like lipopigments in the myocardial fibers, slight to severe fibrosis and infiltration of fat cells in the myocardium. The lipopigments both in the heart and in neurons of the CNS had curvilinear profiles on electron microscope and reacted immunohistochemically to polyclonal antibodies against subunit $c$ of mitochondrial adenosine triphosphate (ATP) synthase. The degenerative process in this heart muscle disease might be attributable to the same metabolic abnormality as seen in the neuronal degeneration associated with Kufs' disease.

(Internal Medicine 34: 1158-1163, 1995)

Key words: lethal arrhythmia, lipofuscin-like lipopigments, subunit c of mitochondrial adenosine triphosphate (ATP) synthase

\section{Introduction}

Kufs' disease (1) is an adult onset form of a group of lysosomal storage disorders, known as neuronal ceroid lipofuscinosis (NCL). Clinical features of Kufs' disease include seizures, myoclonus, neuropsychiatric change, dementia and motor abnormalities (2). The hallmark of the disorder is an accumulation of abnormal lipopigments with characteristic ultrastructural patterns, curvilinear profiles, in neuronal cells and other cells. Microscopical involvement of visceral organs has been reported in myocardium, hepatocytes, renal tubules, macrophages and intestinal mucosa (3-5), but macroscopical involvement of visceral organs has never been reported. Here, we report two autopsy cases in a family with Kufs' disease and heart muscle disease in whom an accumulation of abnormal lipopigments with curvilinear profiles was observed by electron microscope.

\section{Case Profiles}

\section{Pedigree}

Case 1 was the nephew of Case 2. Parents of Case 1 had a consanguineous marriage. The elder brother of Case 2 had difficulty in walking, became bed-ridden and died of pneumonia at the age of 44 .

\section{Case 1}

This patient had difficulty in walking and became demented at the age of 36. Neurological examination revealed dementia, dysarthria, rigidity, fine tremor of the whole body and brisk tendon reflexes at the age of 37 . His optic fundi had neither optic atrophy nor cherry-red spots. He was diagnosed as having Kufs' disease on the basis of a skin biopsy that showed fingerprint profiles of abnormally accumulated lipopigments in the cells of apocrine gland. The fingerprint profiles consisted of systems of paired parallel lines, either straight or curved. At the age of 44 , the patient showed no cardiomegaly. On November 2, 1991, his blood pressure was $108 / 74 \mathrm{mmHg}$ and the heart rate $108 \mathrm{bps}$

\footnotetext{
From the Departments of Neurology, *Neuropathology, National Saigata Hospital, Niigata, **the Department of Neurology, National Nishiojiya Hospital, Niigata, ***the Department of Ultrastructure Research, Psychiatric Research Institute of Tokyo, Tokyo and ****the Department of Biochemistry, Juntendo University School of Medicine, Tokyo

Received for publication October 18, 1994; Accepted for publication August 23, 1995

Reprint requests should be addressed to Dr. Ken-ichi Sakajiri, the Department of Neurology, Kanazawa University School of Medicine, 13-1 Takaramachi, Kanazawa 920
} 
with a normal sinus rhythm. On September 1, 1992, the electrocardiogram (ECG) showed atrial fibrillation, complete A-V block and low amplitude and QRS waves showed the patterns of a right bundle branch block with QS patterns in $\mathrm{I}, \mathrm{aV}_{\mathrm{L}}$ and $\mathrm{V}_{6}$ (Fig. 1a). At the age of 47 , this patient showed signs of cardiomegaly and the cardio-thoracic ratio as seen on the chest $\mathrm{X}$-ray was $67 \%$, while a complete right bundle branch block was found on the ECG. When he was 48, his Holter ECG

a

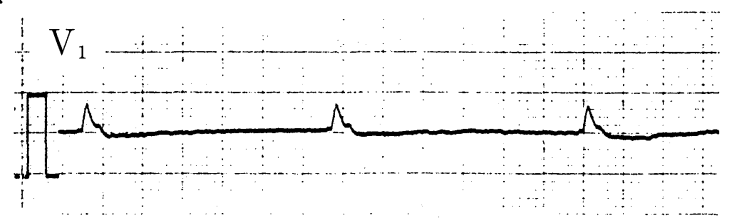

I

II III<smiles>C=CC(C)CCC</smiles>

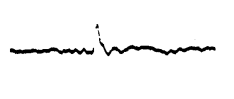

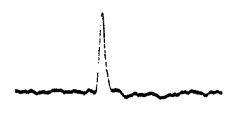

$\mathrm{aV}_{\mathrm{R}}$

$\mathrm{aV}_{\mathrm{L}}$

$\mathrm{aV}_{\mathrm{F}}$
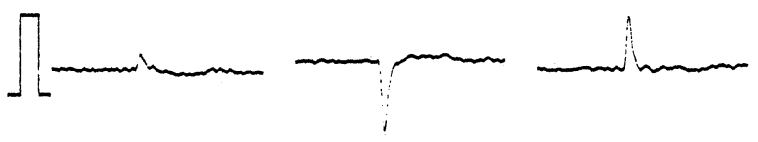

$\mathrm{V}_{1}$

$\mathrm{V}_{2}$

$\mathrm{V}_{3}$

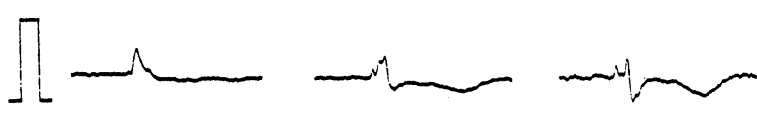

$\mathrm{V}_{4}$

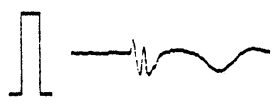

showed non-sustained ventricular tachycardia which continued for 10 beats. Echocardiography showed that wall motion was diffusely hypokinesic and had the following dimensions: left ventricular end-diastolic, $4.7 \mathrm{~cm}$; left ventricular end-systolic, $4.0 \mathrm{~cm}$; right ventricular, $2.8 \mathrm{~cm}$. In addition, it showed an interventricular septal thickness of $10 \mathrm{~mm}$, left ventricular posterior wall thickness of $9 \mathrm{~mm}$, an ejection fraction of $31 \%$ and second degree regurgitation of the pulmonary valve and

b

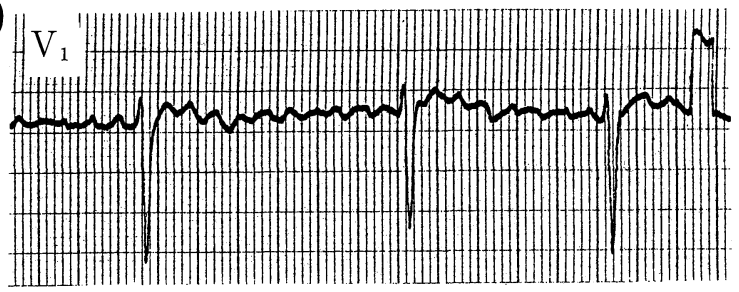

I

II

III
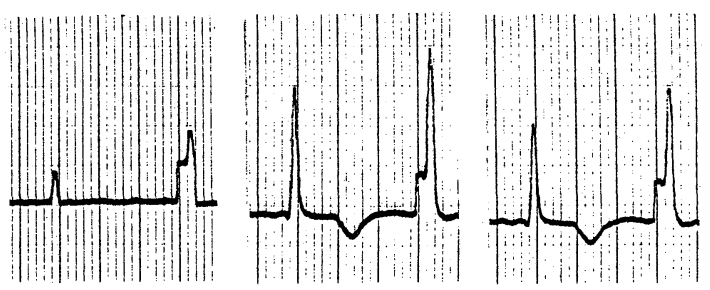

$\mathrm{aV}_{\mathrm{R}}$

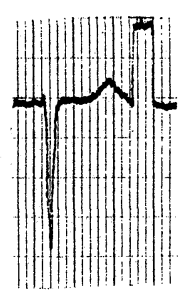

$\mathrm{aV} \mathrm{L}_{\mathrm{L}}$

$\mathrm{aV}_{\mathrm{F}}$
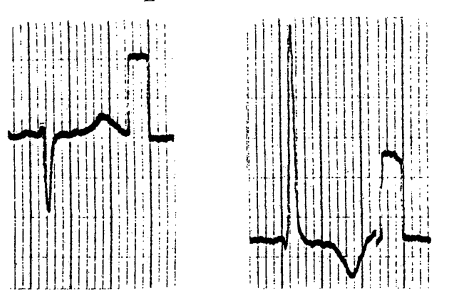

$\mathrm{V}_{1}$

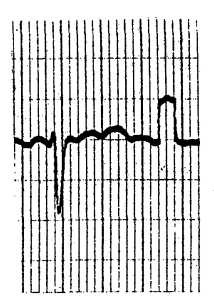

$\mathrm{V}_{2}$

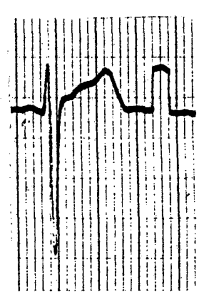

$\mathrm{V}_{3}$

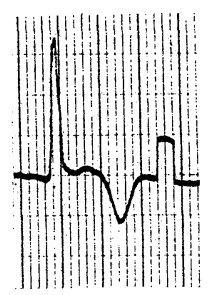

$\mathrm{V}_{4}$

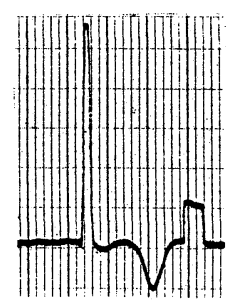

$\mathrm{V}_{5}$

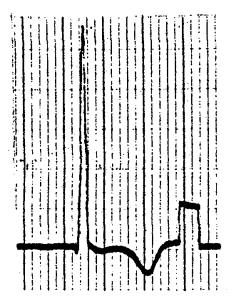

$\mathrm{V}_{6}$

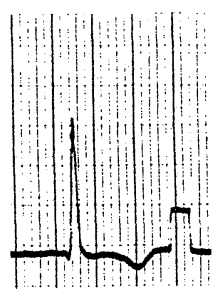

Figure 1. Electrocardiography of the present two patients. a) ECG of Case 1 on September 1, 1992. QTc=0.76, b) ECG of Case 2 on June 7, 1976. $V_{1 S}+V_{5 R}=36 \mathrm{mV}$. 
tricuspid valve. The patient died of cardiac arrest attributable to ventricular tachycardia due to heart failure at the age of 48 .

\section{Case 2}

This patient had suffered from "démarche à petits pas" (6) since the age of 41 and suffered from dementia from the age of 46. The patient was admitted to the National Saigata Hospital when he was 48 . Neurologically, he showed severe dementia, dysarthria, bradykinesia, paretic gait, and brisk tendon reflexes. He developed a Parkinsonian posture, but did not respond to administration of L-Dopa. On June 7, 1976, an ECG showed atrial fibrillation, inverted $\mathrm{T}$ wave in II, III, $\mathrm{aV}_{\mathrm{F}}$, and $\mathrm{V}_{3-6}$ and mild hypertrophy of the left ventricular wall of the heart (Fig. 1b). Two months before death, he was resuscitated from a sudden cardiac arrest of unknown etiology. He died of pneumonia at the age of 49 .

\section{Autopsy Findings}

\section{Case 1}

The brain weighed $895 \mathrm{~g}$. Diffuse and severe atrophy of the cerebral cortex and moderate dilatation of the lateral and third ventricles were seen. Most of the neurons in the central nervous system (CNS) had marked accumulation of lipofuscin-like lipopigments that were stained positively with periodic acidSchiff (PAS) and Sudan Black B and were autofluorescent (Fig. 2a). The lipopigments of the cerebral cortex neurons showed curvilinear profiles under an electron microscope (Fig. 3a).

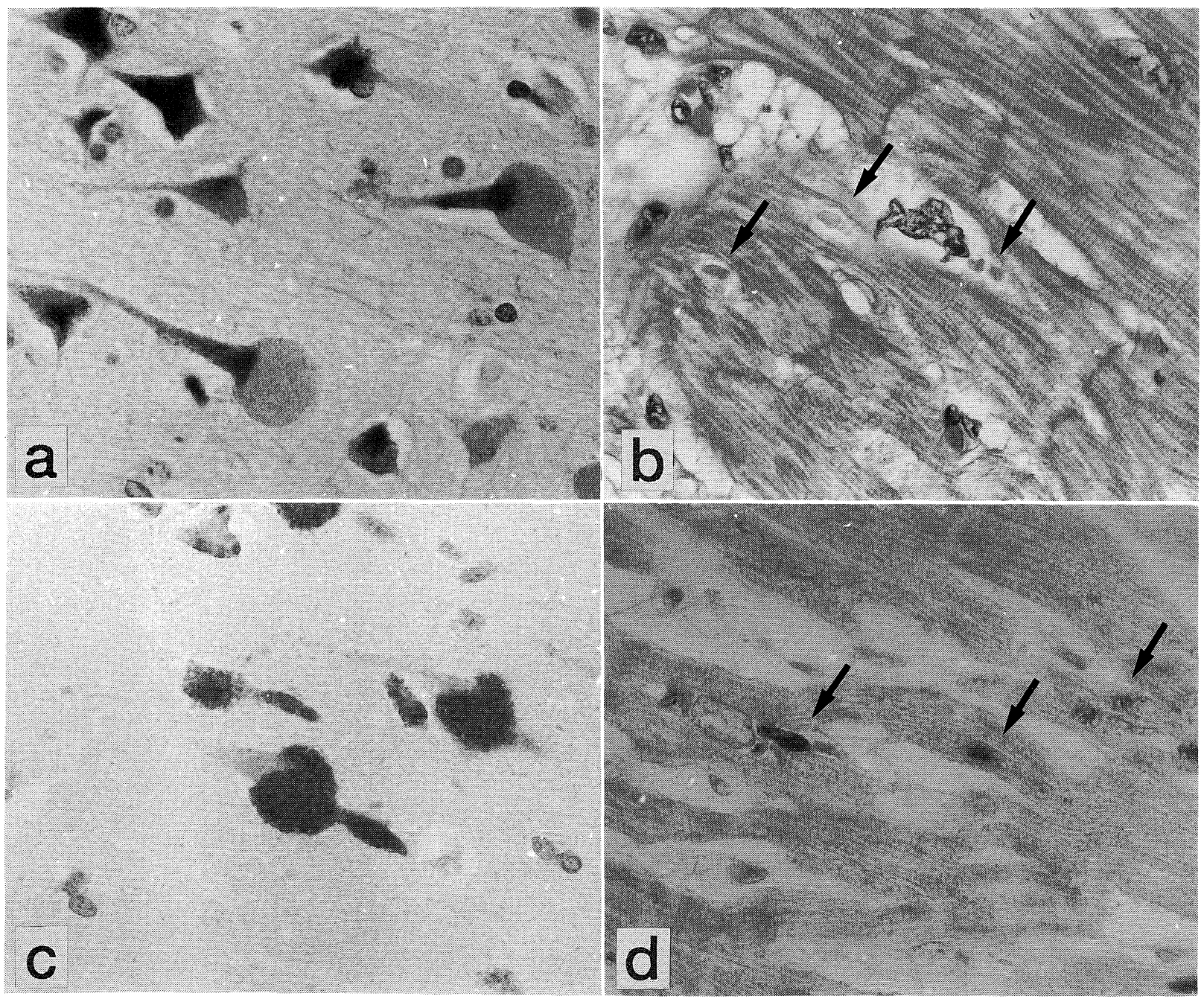

Figure 2. Cytoplasmic lipopigments and immunostaining with antibody to subunit c in Case 1. a) Klüver-Barrera stain of cerebral cortex; $\times 600$. Note abundant lipofuscin-like lipopigments in many neurons stained by Luxol Fast Blue. The cytoplasms are swollen. b) Hematoxylin-eosin stain of the left ventricular wall of the heart; $\times 600$. Note lipofuscin-like lipopigments in the myocardial fibers, especially in the perinuclear region (arrows). c) Markedly positive immunostaining of lipofuscin-like lipopigments in the neurons of the cerebral cortex. Immunoreactivity in the cytoplasm and proximal axon is shown; $\times 600$. d) Increased immunoreactivity of lipofuscin-like lipopigments in the myocardial fibers (arrows); $\times 600$. 

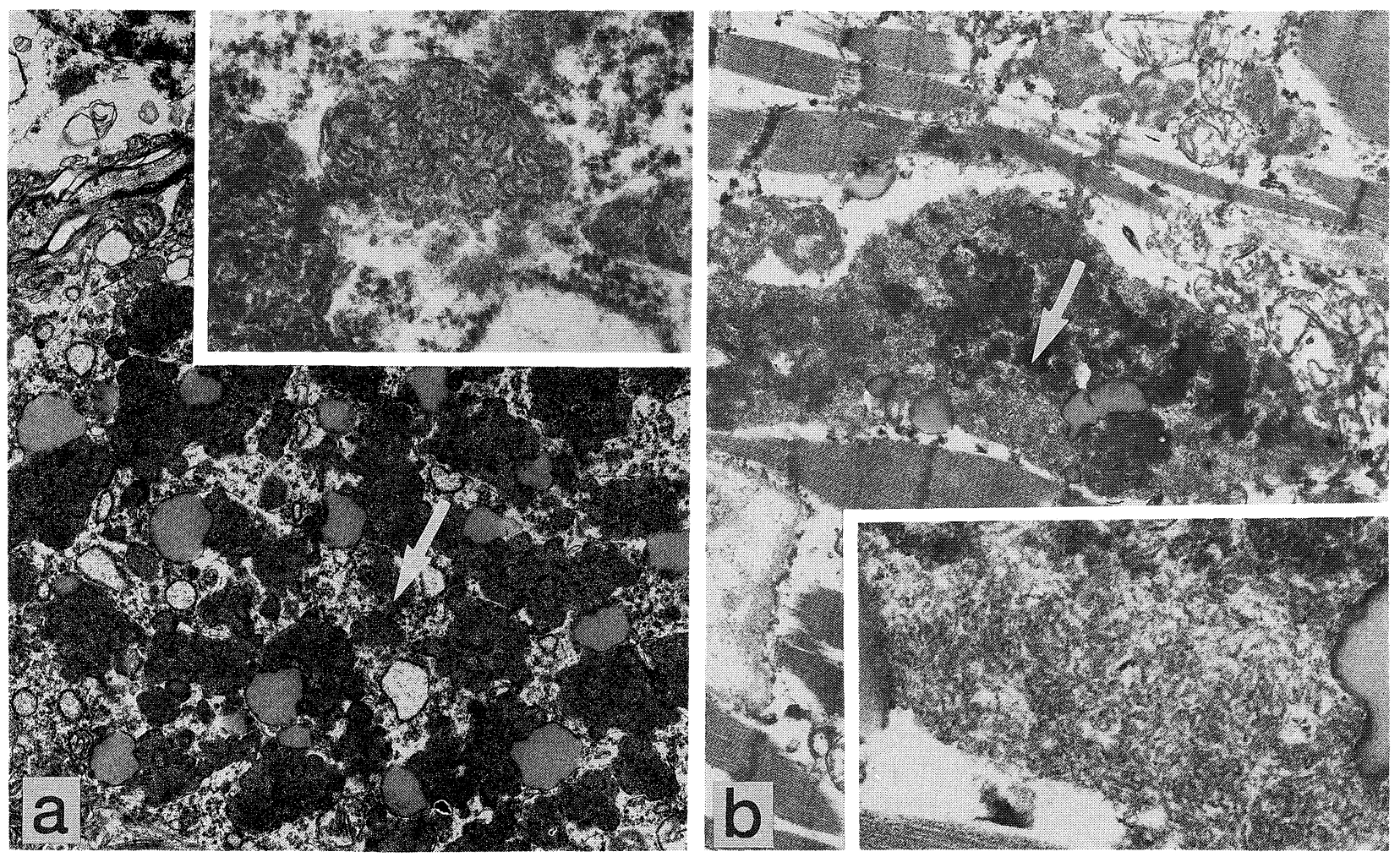

Figure 3. Ultrastructure of abnormal lipopigments in Case 1. a) Deposition of lipopigments (arrow) in the neurons of the cerebral cortex; $\times \mathbf{8 , 0 0 0}$. Insert: Higher magnification, showing both granular pattern and curvilinear profiles; $\times 37,000 . b$ ) Deposition of lipopigments (arrow) in the heart; $\times \mathbf{8 , 0 0 0}$. Insert: Higher magnification, showing both granular pattern and curvilinear profiles in the myocardial fibers; $\times 33,000$.

Immunohistochemical examination showed that the lipopigments reacted markedly to polyclonal antibodies (pAbs) against subunit $\mathrm{c}$ of mitochondrial ATP synthase (Fig. 2c). PAbs were raised against a synthetic peptide corresponding to residues $1-11$ of the $\mathrm{N}$-terminal sequence in subunit $\mathrm{c}$ of mitochondrial ATP synthase; the characteristics of the antibodies were determined previously (7).

The heart weighed $445 \mathrm{~g}$ and showed mild dilatation of the right atrium and ventricle due to pulmonary congestion. The walls of neither ventricle were thickened, while severe fibrosis and infiltration of fat cells were present in the myocardium (Fig. 4a). This case had greater accumulation of lipopigments in the myocardial fibers of the perinuclear region than did normal controls (Fig. 4c). Staining of the lipopigments by PAS and Sudan Black B was the same as that of CNS neurons. Under an electron microscope, the lipopigments in the cardiocytes showed curvilinear profiles also very similar to those in the neurons of the CNS (Fig. 3b). Furthermore a slight increase in the accumulation of lipopigments was seen in the sinoatrial node, the atrioventricular node and in the proximal part of the right bundle branch, although no noticeable increase could be detected in the autonomic ganglion cells of the atrium. Immunohistochemical examination showed that the lipopigments of the myocardial fibers also reacted markedly to antibodies against subunit c of mitochondrial ATP synthase (Fig. 2d).

\section{Case 2}

The brain weighed $1,050 \mathrm{~g}$. The cerebral cortex was mildly atrophic and the ventricular system not dilated. Immunohistochemical and electron microscopic examination of the neurons of the CNS produced very similar findings to those of Case 1 . The heart weighed $400 \mathrm{~g}$. Macroscopic findings revealed no disproportionate hypertrophy, but only mild hypertrophy of the left ventricle with a left and right ventricular wall thickness of $14 \mathrm{~mm}$ and $4 \mathrm{~mm}$, respectively, which no dilatation of either ventricle nor any myocardial infarct was seen. Light microscopic findings revealed minor patchy and interstitial fibrosis without myocardial disarray. The myocardial fibers showed a slight increase in the accumulation of lipopigments, very similar to that in Case 1 (Fig. 4b, d). Immunohistochemical examination showed that the lipopigments of the myocardial fibers also reacted markedly to antibodies against subunit $\mathrm{c}$ of mitochondrial ATP synthase.

\section{Discussion}

The autopsy findings of the present two cases showed an abundant accumulation of lipofuscin-like lipopigments in most 

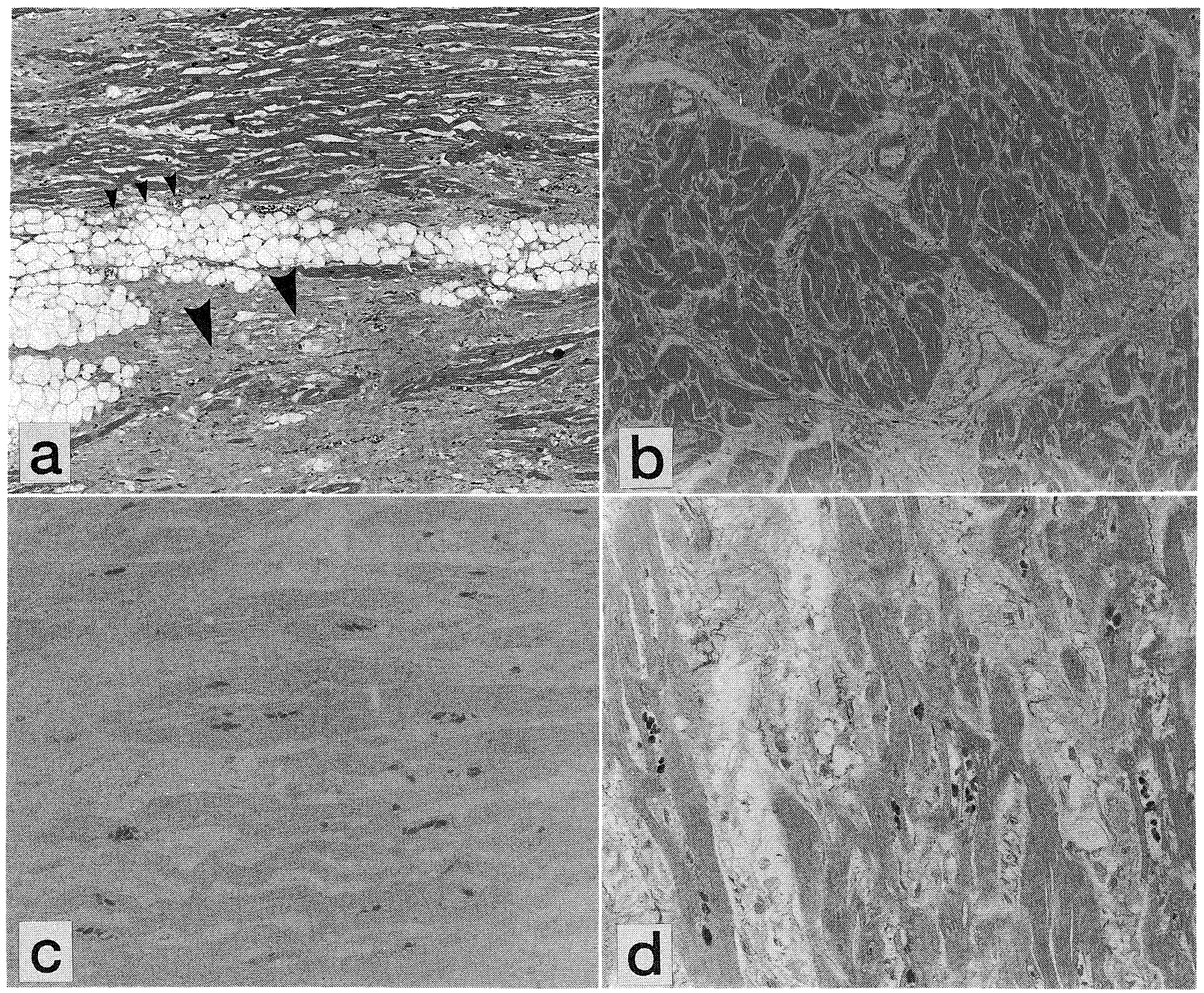

Figure 4. Microscopical changes in the hearts of the present two patients. a) Severe fibrosis and infiltration of fat cells in Case 1. Bigger arrowheads show severe fibrosis. Smaller arrowheads show infiltration of fat cells $($ HE stain, $\times 50)$. b) Minor fibrosis in Case 2 (HE stain, $\times 85$ ). c) Slight increase in the accumulation of lipopigments at perinuclear poles in Case 1 (Sudan Black B stain, $\times 200$ ). d) Slight increase in the accumulation of lipopigments at perinuclear poles in Case 2 (Elastica-Goldner stain, $\times \mathbf{2 0 0})$.

CNS neurons. They were both diagnosed as having an adult onset form of neuronal ceroid lipofuscinosis (Kufs' disease) because the lipopigments showed curvilinear profiles under electron microscope. Such curvilinear bodies are found consistently in lysosomes. Two types of curvilinear bodies have been identified in published electron micrographs. The first variety, type A curvilinear bodies, is found in NCL and shows up as small electron-dense bodies with a C-shaped or worm-like profile about 15 to $20 \mathrm{~nm}$ thick, the average width of the curved profiles being about $0.1 \mu \mathrm{m}$. Ultrastructurally the lysosomes containing these curvilinear bodies do not resemble lipofuscin granules, but, like lipofuscin, they are golden yellow and autofluorescent (8). The second reason why we diagnosed the two cases as having Kufs' disease was that the lipopigments showed immunoreactivity to antibodies. Storage materials in Kufs' disease were recently reported to contain a proteolipid and the entire subunit $c$ of mitochondrial ATP synthase (9). Immunohistochemical studies have shown subunit c of mitochondrial ATP synthase to react positively also in lateinfantile, juvenile and adult NCL (10).

Involvement of visceral organs, including the heart, in Kufs' disease has been reported previously (3-5). These reports showed microscopic, but no macroscopic involvement in the heart. In a case of juvenile NCL, abnormal lipopigments were mainly localized in the perinuclear region of the myocardial fibers (11). Reske-Nielsen et al (12) reported cardiac involvement in 13 autopsied patients with juvenile amaurotic idiocy who had a large amount of lipopigments at the nuclear poles of cardiac muscle cells, while in four cases most of the ganglionic cells had ballooned and contained large amounts of lipopigments or calcium compounds. Moreover, electron microscopic examination showed the lipopigments to be mostly granular but 
also to have curvilinear profiles. Another case of juvenile NCL showed ventricular hypertrophy on echocardiography and several series of cardiac arrhythmias including ventricular tachycardia during Holter monitoring (13). Several series of cardiac arrhythmia have been reported in canine ceroid lipofuscinosis and an accumulation of abnormal lipopigments was found in the autonomic ganglion cells of the atrium and in the myocardial fibers of the ventricle (14). Some microscopical evidence for storage $(3,4)$ was found in the heart of a case with Kufs' disease, but these findings were inconsistent and minimal.

The present two cases, however, showed distinct evidence of heart muscle disease, especially Case 1 , since macroscopic examination of the heart showed marked fibrosis and lipogenetic change. The hearts of these two cases showed that both hypertrophy and dilatation were only mild, while in cases of juvenile amaurotic idiocy (12), slight to moderate changes involving hypertrophy are seen. Microscopically the myocardium of Case 1 showed severe fibrosis, infiltration of fat cells and a slight increase in the accumulation of lipopigments at the nuclear poles, while the hearts in the cases just mentioned (12) had large amounts of lipopigments in the majority of cells at the nuclear poles. The conduction system of Case 1 showed a mild accumulation of lipopigments only in the sinoatrial node, the atrioventricular node and the proximal part of the right bundle branch, while depositions of lipopigments, calcium and cholesterol compounds were seen in varying amounts throughout the conduction tissue in the juvenile amaurotic idiocy cases (12).

Heart muscle disease does not necessarily exclude the possibility of coincidental complication of idioipathic cardiomyopathy with Kufs' disease. However, coincidence of the same clinicopatholoical features in two patients of the same family is implausible. We therefore considered the pathological change in the heart of Case 1 not to be related to idiopathic cardiomyopathy because our cases showed that both hypertrophy and dilatation were only mild and that the arrangement of the myocardial fibers was normal. Several findings of arrhythmia in our cases might be attributable to degeneration of the muscle fibers rather than to the accumulation of lipopigments, because only a minor amount of lipopigments was seen. However, we do not categorically exclude the possibility that the arrhythmias might be attributable to the autonomic ganglion cells of the myocardium, because we could not examine the entire myocardium.

Abnormal lipopigments of the heart muscle of Case 1 showed curvilinear profiles very similar to those seen in the CNS and reacted immunohistochemically to antibodies against subunit c of mitochondrial ATP synthase. Recently, an immunohistochemical study showed an increased reactivity to subunit c of mitochondrial ATP synthase in mucopolysacchariodsis type I and type III as well as in NCL (15). Accumulation of proteolipids might well be related to the degenerative changes in those diseases. Degenerative changes in the myocardium of our cases might thus be attributable to the same metabolic disturbances as those in the neurons, because the lipopigments of the myocardium and the neuronal cells showed the same ultrastructural and immunohistochemical patterns.

Acknowledgements: We would like to thank Yoshio Igarashi for his outstanding technical support. This study was supported by a Research Grant (5A-9) for Nervous and Mental Disorders from the Ministry of Health and Welfare, Japan.

\section{References}

1) Kufs VH. Uber eine Spatform der amaurotischen Idiotie und ihre heredofamiliaren Grundlage. Z Ges Neurol Psych 95: 169, 1925 (in German)

2) Berkovic SF, Carpenter S, Andermann F, Andermann E, Wolfe LS. Kufs' disease: A critical reappraisal. Brain 111: 27, 1988.

3) Pallis CA, Duckett S, Pearse AGE. Diffuse lipofuscinosis of the central nervous system. Neurology 17: 381, 1967.

4) Dom R, Brucher JM, Ceuterick C, Carton H, Martin JJ. Adult ceroidlipofuscinosis (Kufs' disease) in two brothers. Retinal and visceral storage in one; diagnostic muscle biopsy in the other. Acta Neuropathol (Berlin) 45: 67, 1979.

5) Goebel HH, Braak H, Seidel D, Doshi R, Marsden CD, Gullota F. Morphologic studies on adult neuronal-ceroid lipofuscinosis (NCL). Clin Neuropathol 1: 151, 1982.

6) Hayashi S, Oyanagi S, Wakabayashi M. Electron-microscopic study of a case of adult ceroid-lipofuscinosis (Kufs' disease): Appearance of the creation of lipopigments. Studies of the clinical features, pathogenesis and treatment of senile brain disorders. The Research Grant for Nervous Disorders from the Ministry of Health and Welfare, 47, 1985.

7) Kominami E, Ezaki J, Muno D, Ishido K, Ueno T, Wolfe LS. Specific storage of subunit $\mathrm{c}$ of mitochondrial ATP synthase in lysosomes of neuronal ceroid lipofuscinosis (Batten's disease). J Biochem 111: 278, 1992.

8) Ghadially FN. Curvilinear Bodies in Lysosomes. in: Ultrastructural Pathology of the Cell and Matrix, 3rd Ed. Butterworths, London, 1988.

9) Palmer DN, Fearnley IM, Medd SM, Walker JE, Martinus RD, Bayliss SL. Lysosomal storage of the DCCD reactive proteolipid subunit of mitochondrial ATP synthase in human and ovine ceroid lipofuscinosis. Adv Exp Med Biol 266: 211, 1989.

10) Hall NA, Lake BD, Dewji NN, Patrick AD. Lysosomal storage of subunit c of mitochondrial ATP synthase in Batten's disease (ceroidlipofuscinosis). Biochem J 275: 269, 1991.

11) Kristensson $K$, Rayner $S$, Sourander $P$. Visceral involvement in juvenile amaurotic idiocy. Acta Neuropathol 4: 421, 1965.

12) Reske-Nielsen E, Baandrup U, Bjerregaard P, Bruun I. Cardiac involvement in juvenile amaurotic idiocy - A specific heart muscle disorder. Histological findings in 13 autopsied patients. Acta Microbiol Scand Sect A 89: 357, 1981.

13) Michielsen P, Martin JJ, Vanagt E, Vrints C, Gillebert T, Snoeck J. Cardiac involvement in juvenile ceroid lipofuscinosis of the SpielmeyerVogt-Sjögren type: Prospective noninvasive findings in two siblings. Eur Neurol 23: 166, 1984.

14) Armstrong D, Lombard C, Ellis A. Electrocardiographic and histologic abnormalities in canine ceroid-lipofuscinosis (CCL). J Mol Cell Cardiol 18: 91,1986

15) Kida E, Wisniewski KE, Golabek AA. Increased expression of subunit c of mitochondrial ATP synthase in brain tissue from neuronal ceroid lipofuscinoses and mucopolysaccharidosis cases but not in long-term fibroblast cultures. Neurosci Lett 159: 1, 1993. 